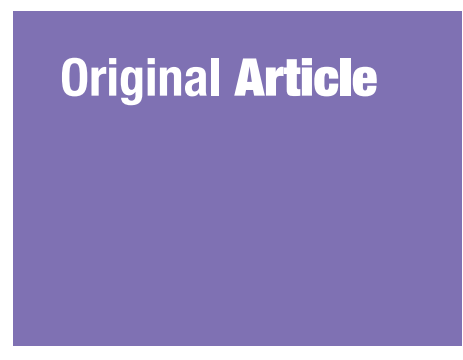

Submitted: 7 Jan 2019

Accepted: 3 May 2019

Online: 28 Jun 2019

\section{Adverse Outcomes of Perioperative Red Blood Cell Transfusions in Coronary Artery Bypass Grafting in Hospital Universiti Sains Malaysia}

\author{
Choon Hua Chan ${ }^{1}$, Ghazali Mohamad Ziyadi ${ }^{2}$, Mamat Ahmad \\ ZUHDI $^{2}$
}

1 Department of Surgery, School of Medical Sciences, Universiti Sains Malaysia, Kubang Kerian, Kelantan, Malaysia

2 Unit of Cardiothoracic Surgery, Department of Surgery, School of Medical Sciences, Universiti Sains Malaysia, Kubang Kerian, Kelantan, Malaysia

To cite this article: Chan CH, Mohamad Ziyadi G, Ahmad Zuhdi M. Adverse outcomes of perioperative red blood cell transfusions in coronary artery bypass grafting in Hospital Universiti Sains Malaysia. Malays $J$ Med Sci. 2019;26(3):49-63. https://doi.org/10.21315/mjms2019.26.3.4

To link to this article: https://doi.org/10.21315/mjms2019.26.3.4

\title{
Abstract
}

Background: Perioperative red blood cell (RBC) transfusion in coronary artery bypass grafting (CABG) has both benefits and harms. Our aim was to study the association between perioperative RBC transfusion and its adverse outcomes.

Methods: This was a retrospective study of patients who underwent isolated CABG in Hospital Universiti Sains Malaysia, Kelantan, Malaysia, from 1 January 2013 until 31 December 2017. Data were collected from medical records, and comparisons were made between patients who received perioperative RBC transfusions and those who did not have adverse outcomes after CABG.

Results: A total of 108 patients who underwent isolated CABG were included in our study, and 78 patients received perioperative $\mathrm{RBC}$ transfusions. Patients who received perioperative RBC transfusions compared to those who did not were significantly more likely to develop prolonged ventilatory support $(21.8 \%$ versus $0 \%, P=0.003)$, cardiac morbidity $(14.1 \%$ versus $0 \%$, $P=0.032)$, renal morbidity $(28.2 \%$ versus $3.3 \%, P=0.005)$ and serious infection $(20.5 \%$ versus $3.3 \%, P=0.037)$. With each unit of packed RBC transfusions, there was a significantly increased risk of prolonged ventilatory support (adjusted odds ratio $[A O R]=1.45 ; 95 \%$ confidence interval $[C I]=1.20-1.77 ; P<0.001)$, cardiac morbidity $(A O R=1.40 ; 95 \% C I=1.01-1.79 ; P=0.007)$, renal morbidity $(\mathrm{AOR}=1.23 ; 95 \% \mathrm{CI}=1.03-1.45 ; P=0.019)$ and serious infection $(\mathrm{AOR}=1.31 ; 95 \% \mathrm{CI}=$ 1.07-1.60; $P=0.009)$.

Conclusion: Perioperative RBC transfusion in isolated CABG patients is associated with increased risks of developing adverse events such as prolonged ventilatory support, cardiac morbidity, renal morbidity and serious infection.

Keywords: adverse outcomes, morbidity, red blood cell, perioperative transfusions, CABG, Malaysia

\section{Introduction}

Coronary artery disease (CAD) is the leading cause of mortality worldwide and in Malaysia (1). According to the World Health Organization, in Malaysia, CAD accounted for
29,400 deaths in 2012, which is equal to 98.9 deaths per 100,000 in the population. CAD also accounts for $20.1 \%$ of all mortalities in the country (2). CAD is one of the major burdens of hospitals according to the Ministry of Health. According to the hospital admission records and 
death certifications, CAD accounted for 6.99\% of total hospital admissions and $23.34 \%$ of all hospital deaths in 2014 (1).

Treatments for CAD include pharmacological therapy and interventions such as percutaneous coronary intervention (PCI) or coronary artery bypass grafting (CABG). CABG has been the standard of care for the revascularisation of patients with complex CAD since its introduction in 1968 (3). Current evidence has demonstrated a survival benefit with CABG over PCI in patients with three or more vessel disease as well as those with complex coronary artery anatomy. Mohr et al. (4) randomised 1800 patients with left main coronary disease or three-vessel disease to either CABG or PCI. The 5-year study demonstrated a higher survival rate in the CABG group than in the PCI group for patients with complex multivessel coronary artery disease.

According to the 2014 European Society of Cardiology (ESC)/European Association for Cardio-Thoracic Surgery (EACTS) guidelines on myocardial revascularisation, the mortality rate associated with $\mathrm{CABG}$ is $1 \%-2 \%$, and the morbidity rate is $1 \%-2 \%$ for each of the following events: stroke; renal, pulmonary and cardiac failure; bleeding; and wound infections (5). The 2011 American College of Cardiology Foundation (ACCF)/American Heart Association (AHA) guidelines for CABG surgery reported that elderly and female patients with diabetes mellitus, chronic obstructive pulmonary disease/ respiratory insufficiency, end-stage renal disease on dialysis, concomitant peripheral vascular disease, previous stroke and reoperative CABG are associated with higher rates of morbidity and mortality (6).

The 2011 ACCF/AHA guidelines for CABG surgery recommended a blood conservation strategy in CABG surgery (6). Blood conservation practices in cardiac surgery were introduced in the 1970 s because of the scarcity and cost of this limited resource, the awareness of transfusion-borne infections such as hepatitis B and $\mathrm{C}$ and human immunodeficiency virus and the increasing awareness of the immunologic implications of this allogeneic exposure (7).

The rationale for perioperative red blood cell (RBC) transfusions is based on observations that anaemia is an independent risk factor for morbidity and mortality after cardiac operations $(8,9)$. However, numerous studies have demonstrated that perioperative $\mathrm{RBC}$ transfusions in patients undergoing cardiac operations including CABG have been associated with higher rates of morbidity and mortality (10-16). Perioperative blood transfusions have been linked to higher rates of post-operative renal dysfunction (17); neurologic, respiratory and cardiac complications $(12-14,18)$; serious infection $(7,19,20)$; prolonged ventilatory support (12-14); prolonged length of stay (2123); and short-term and long-term survival (2431).

The aims of this study are to determine the association between perioperative packed RBC transfusions and adverse outcomes after isolated CABG and to further determine any incremental risk associated with each unit of packed $\mathrm{RBC}$ transfusions on morbidity after CABG.

\section{Methodology}

\section{Study Design}

This was a retrospective medical record review and a single-centre study at Hospital Universiti Sains Malaysia (HUSM), Kelantan, Malaysia. The study subjects were patients who were diagnosed with CAD and who underwent isolated CABG at HUSM from 1 January 2013 until 31 December 2017. All procedures were performed by the same two cardiothoracic surgeons. The study protocol was reviewed and approved by the Human Research Ethics Committee of Universiti Sains Malaysia (JEPeM). A stratified sampling method was used to select samples.

Patients who fulfilled the inclusion and exclusion criteria were recruited in our study. Inclusion criteria:

1. Patients who underwent isolated $\mathrm{CABG}$ at HUSM from 1 January 2013 until 31 December 2017

2. Patients more than 18 years old Exclusion criteria:

1. Patients who underwent combination surgery (e.g. CABG and valve replacement)

2. Patients who underwent isolated CABG with missing or incomplete data

Patients' case notes were reviewed, and the information collected included patient demographics, comorbidities, cardiac status [left ventricular ejection fraction (LVEF) and New York Heart Association (NYHA) classification], clinical presentation, diseased coronary vessel/ vessels, laboratory parameters (haemoglobin, 
haematocrit, blood urea and creatinine level), American Society of Anaesthesiologists (ASA) classification, operative information (duration of surgery, operative status, number of bypasses performed, cardiopulmonary bypass time, aortic cross clamp time, and intra-operative and immediate post-operative complications), number of packed RBC transfusions, complications post-surgery (prolonged ventilatory support, cardiac morbidity, neurologic morbidity, renal morbidity, serious infection and mortality) and re-operation. Based on the EuroSCORE measurement, LVEF was classified as normal (LVEF > 50\%), moderate (LVEF $31 \%-49 \%$ ) or poor (LVEF < 30\%) (32).

Data were grouped according to patients who received perioperative $\mathrm{RBC}$ transfusions and those who did not. The outcome of interest was complications (prolonged post-operative ventilatory support, cardiac morbidity, neurologic morbidity, renal morbidity, serious infection and post-operative mortality) after CABG among the two groups of subjects.

\section{Operational Definitions}

The terms used in this study were defined as follows:

1. Perioperative RBC transfusion, defined as a transfusion of RBCs during the preoperative, intra-operative and/or postoperative period. Autologous blood transfusions were excluded.

2. Prolonged post-operative ventilatory support, defined as mechanical ventilatory support for more than $72 \mathrm{~h}$ post-operatively.

3. Cardiac morbidity, defined as a low cardiac index $(1.8 \mathrm{~L} / \mathrm{min} / \mathrm{m} 2)$ despite adequate fluid replacement and administration of high-dose inotropic agents for $>4 \mathrm{~h}$ or post-operative myocardial infarction.

4. Neurologic morbidity, defined as focal or global neurologic deficits (stroke), as evidenced by clinical or imaging (brain CT) findings.

5. Renal morbidity, defined as new onset of renal failure requiring dialysis or acute kidney injury defined by the Kidney Disease Improving Global Outcomes (KDIGO) criteria:

- Increase in serum creatinine by $0.3 \mathrm{mg} /$ $\mathrm{dL}$ or more within 48 hours or
- Increase in serum creatinine to 1.5 times the baseline or more within the last 7 days or

- Urine output less than $0.5 \mathrm{~mL} / \mathrm{kg} / \mathrm{h}$ for $6 \mathrm{~h}$

1. Serious infection, defined as sepsis syndrome, septic shock, pneumonia, mediastinitis, or sternal or leg wound infection. In addition, the diagnosis of sepsis included organisms isolated from the cultures along with elevated temperature and white blood cell counts.

2. Mortality, defined as in-hospital or 30-day mortality.

\section{Statistical Analysis}

Data were analysed using Statistical Package for the Social Sciences (SPSS) version 24. Data were double checked and cleaned to screen for errors or missing values. Baseline demographics and information of the patients were described, categorical variables were presented as frequencies (percentages), and continuous variables were presented as the mean \pm standard deviation (SD).

Data were divided into two groups (patients who received perioperative $\mathrm{RBC}$ transfusions and patients who did not); Pearson's chi-square test or Fisher's Exact test for categorical variables and independent-samples $t$-test for continuous variables were used to assess the differences in the characteristics between these two groups. Pearson's chi-square test or Fisher's Exact test were used to determine the association between perioperative $\mathrm{RBC}$ transfusions and each adverse outcome post-CABG. Pearson's chi-square test was used if the expected count of $<5$ was $<20 \%$, and Fisher's Exact test was used if the expected count of $<5$ was $>20 \%$. Adverse outcomes that were significantly associated with perioperative RBC transfusions were further studied for the risks associated with each unit of packed RBC transfusions. Binary logistic regression was used to determine the adjusted odds ratio (AOR) of perioperative $\mathrm{RBC}$ transfusion in association with the studied adverse outcomes. Simple logistic regression was used in univariable analysis to determine variables that were significantly associated with the adverse outcome, and these variables were entered into multiple logistic regression. The forward and backward stepwise likelihood ratio (LR) method was used to determine the AOR of factor/factors that significantly increased the risk of the adverse 
outcome. Multi-collinearity and two-way interactions between variables were checked. Hosmer and Lemeshow test, the area under the receiver operating characteristics (ROC) curve and classification tables were used to test for goodness of fit. AORs with 95\% confidence intervals (CIs) and corresponding $P$-values were obtained. A $P$-value of $<0.05$ was accepted to be statistically significant.

\section{Results}

A total of 108 patients who had isolated CABG performed at HUSM, Kelantan, Malaysia, from 1 January 2013 until 31 December 2017 were included in this study. According to the descriptive analysis, 83 (76.9\%) patients were male and 25 (23.1\%) were female. For the ethnicity, 94 (87\%) patients were Malaysian, 12 (11.1\%) patients were Chinese, and 2 (1.9\%) patients were Indian. A total of 68 (63\%) patients were smokers/ex-smokers, and 78 (72.2\%) patients received perioperative RBC transfusions, with 2 units being the most common (Figure 1). The majority of the procedures, 105 (97.2\%), were elective, and only $3(2.8 \%)$ were emergency procedures. Intra-operative and immediate post-operative complications included bleeding in 1 (0.9\%) patient, cardiac arrhythmia in 1 (0.9\%) patient and poor cardiac contractility in $2(1.9 \%)$ patients. There were 2 (1.9\%) patients who required reoperation. Post-operative complications included prolonged ventilatory support in 17 (15.7\%) patients, cardiac morbidity in $11(10.2 \%)$ patients, neurologic morbidity in 2 (1.9\%) patients, renal morbidity in $23(21.3 \%)$ patients, serious infection in $17(15.7 \%)$ patients and mortality in 5 (4.6\%) patients.

Comparing the transfused and nontransfused groups (Table 1), patients who received perioperative $\mathrm{RBC}$ transfusions were older (transfused versus non-transfused: 60 years versus 57 years, $P=$ 0.014). Female patients were more likely to receive transfusions than male patients (23.1\% versus $0 \%, P<0.001)$. The majority of the patients were Malaysian (87.2\% versus 86.7\%, $P=0.764$ ), with no difference between the groups. Lower body mass index (BMI) was observed in the transfused group than in the non-transfused group (26.1 versus 28.8, $P=0.005)$. Patients with a comorbidity of diabetes mellitus $(61.5 \%$ versus $40 \%$, $P=0.044)$, hypertension (93.6\% versus $76.7 \%$, $P=0.019)$, and chronic kidney disease (CKD)/ end-stage renal disease (ESRD) (29.5\% versus $10 \%, P=0.034)$ and patients with higher NYHA class (III or IV) (26.9\% versus $3.3 \%, P=0.006)$ and higher ASA class (III and above) (87.2\% versus $66.7 \%, P=0.014$ ) were more likely to have perioperative $\mathrm{RBC}$ transfusions. Preoperatively, patients who received transfusions had significantly lower haemoglobin levels (12.7 versus $15.2, P<0.001)$, lower haematocrit levels (38.1 versus $44.3, P<0.001$ ) and higher blood urea levels (7.3 versus 5.5, $P=0.034$ ) compared to patients who did not receive transfusions. No significant differences in the duration of surgery, cardiopulmonary bypass time, aortic cross clamp time, number of grafts used, intra-operative/ immediate post-operative complication rate or re-operation rate were observed between the groups.

According to the univariate analysis (Table 2), patients who received perioperative RBC transfusions were significantly more likely to have prolonged ventilatory support (21.8\% versus $0 \%, P=0.003)$, cardiac morbidity $(14.1 \%$ versus $0 \%, P=0.032)$, renal morbidity $(28.2 \%$ versus $3.3 \%, P=0.005$ ) and serious infection (20.5\% versus $3.3 \%, P=0.037$ ) than patients who did not receive transfusions. Neurologic morbidity $(2.6 \%$ versus $0 \%, P=1.000)$ and mortality rate $(6.4 \%$ versus $0 \%, P=0.037)$ were also higher in the transfused group than in the non-transfused group, but the differences were not statistically significant. Using logistic regression, the risk-adjusted probability of developing each adverse outcome as a function of RBCs was modelled (Tables 3-6). When adjusted for other factors, we found that, with an increase in one unit of packed RBC transfusions, patients had 1.45 times the odds of developing prolonged ventilatory support (95\%CI, 1.201.77, $P<0.001)$; similar results were found with the other outcomes, with 1.40 times the odds of cardiac morbidity (95\%CI, 1.01-1.79; $P=0.007$ ), 1.23 times the odds of renal morbidity (95\%CI, 1.03-1.45; $P=0.019)$, and 1.31 times the odds of serious infection (95\% CI, 1.07-1.60; $P=0.009$ ). 
Original Article | Adverse outcomes of RBC transfusions in CABG

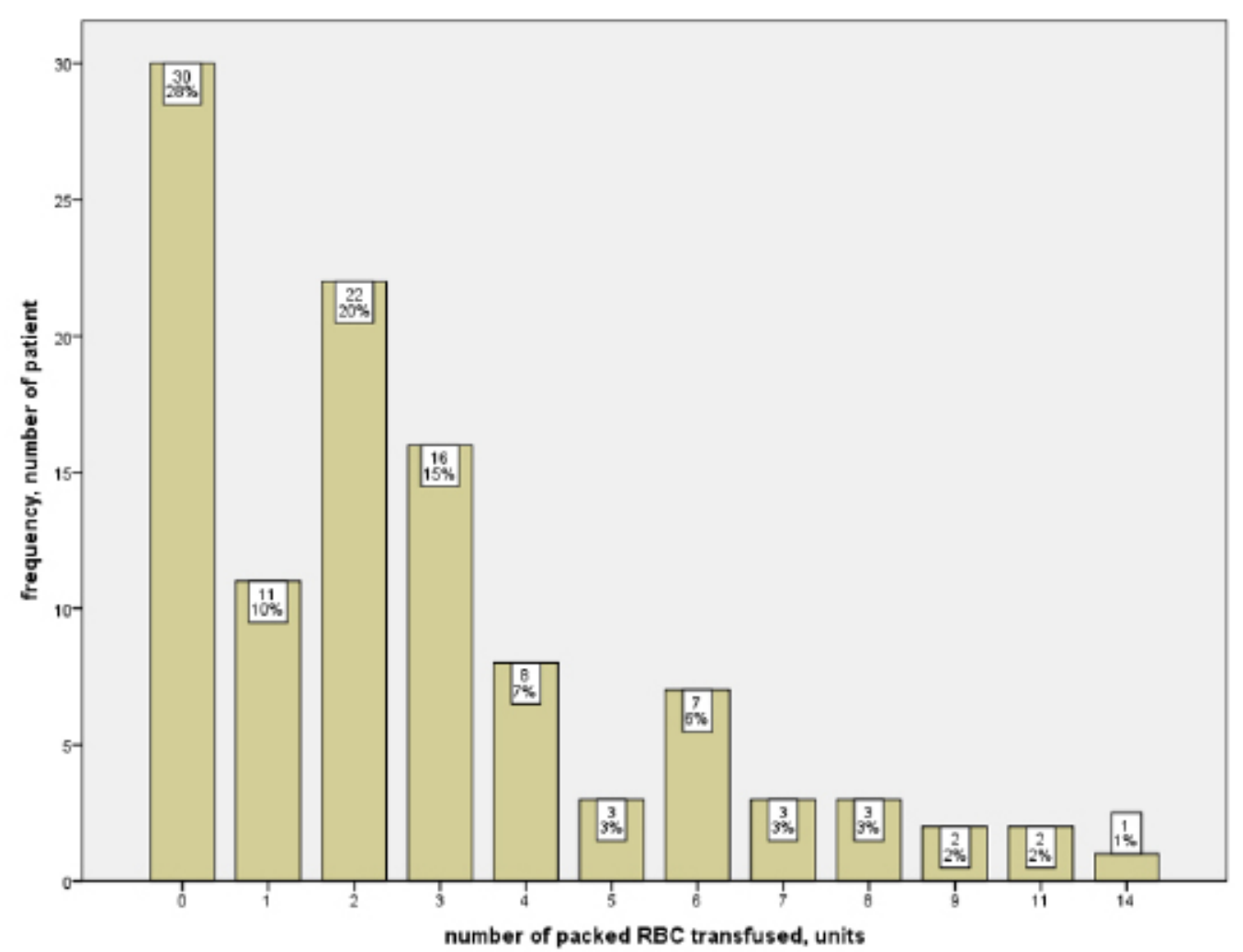

Figure 1. Number of packed red bloods cells tranfused in units for patients who underwent isolated coronary artery bypass grafting

Table 1. Characteristics of patients underwent isolated CABG who received perioperative RBC transfusions and patients who did not

\begin{tabular}{lccc} 
Variables & Transfused $(\boldsymbol{n}=\mathbf{7 8})$ & Not Transfused $(\boldsymbol{n}=\mathbf{3 0})$ & $\boldsymbol{P}$-value \\
Age & $60 \pm 6.9$ & $57 \pm 7.3$ & $0.014^{\mathrm{a}}$ \\
$>65$ & $19(24.4 \%)$ & $3(10 \%)$ & $0.097^{\mathrm{b}}$ \\
Gender & & & \\
Male & $53(67.9 \%)$ & $30(100 \%)$ & $<0.001^{\mathrm{b}}$ \\
Female & $25(23.1 \%)$ & $0(0 \%)$ & \\
Race & & & \\
Malay & $68(87.2 \%)$ & $26(86.7 \%)$ & \\
Chinese & $9(11.5 \%)$ & $3(10 \%)$ & \\
Indian & $1(1.3 \%)$ & $1(3.3 \%)$ & \\
Characters & & & \\
BMI, kg/m & & $28.8 \pm 4.3$ & $0.005^{\mathrm{b}}$ \\
Smoker/ex-smoker & $26.1 \pm 4.3$ & $26(86.7 \%)$ & $0.002^{\mathrm{b}}$ \\
Co-morbidities & $42(53.8 \%)$ & & \\
Diabetes mellitus & & $12(40 \%)$ & $0.044^{\mathrm{b}}$ \\
Hypertension & $48(61.5 \%)$ & $23(76.7 \%)$ & $0.019^{\mathrm{c}}$ \\
Hyperlipidemia & $73(93.6 \%)$ & $27(90 \%)$ & $0.199^{\mathrm{b}}$ \\
\hline
\end{tabular}


Table 1. (continued)

\begin{tabular}{|c|c|c|c|}
\hline Variables & Transfused $(n=78)$ & Not Transfused $(n=30)$ & $P$-value \\
\hline CKD/ESRD & $23(29.5 \%)$ & $3(10 \%)$ & $0.034^{b}$ \\
\hline Previous stroke & $9(11.5 \%)$ & o (o\%) & $0.060^{c}$ \\
\hline Cardiac arrhythmia & $3(3.8 \%)$ & o (o\%) & $0.559^{c}$ \\
\hline COAD/asthma & $3(3.8 \%)$ & o (o\%) & $0.559^{c}$ \\
\hline \multicolumn{4}{|l|}{ Cardiac Status } \\
\hline LVEF > 50\% & $46(59 \%)$ & $23(76.7 \%)$ & $0.086^{\mathrm{b}}$ \\
\hline $\mathrm{LVEF} \leq 50 \%$ & $32(41 \%)$ & $7(23.3 \%)$ & \\
\hline NYHA class I or II & $57(73.1 \%)$ & $29(96.7 \%)$ & $0.006^{\mathrm{b}}$ \\
\hline NYHA class III or IV & $21(26.9 \%)$ & $1(3 \cdot 3 \%)$ & \\
\hline \multicolumn{4}{|l|}{ Clinical Presentation } \\
\hline Stable angina & $5(6.4 \%)$ & $3(10 \%)$ & $0.683^{c}$ \\
\hline Unstable angina & $34(43.6 \%)$ & $13(43.3 \%)$ & $0.981^{b}$ \\
\hline Myocardial infarction & $27(34.6 \%)$ & $14(46.7 \%)$ & $0.248^{b}$ \\
\hline Congestive cardiac failure & $8(10.3 \%)$ & $\mathrm{o}(\mathrm{o} \%)$ & $0.103^{c}$ \\
\hline Cardiogenic shock & $4(5.1 \%)$ & o (o\%) & $0.574^{c}$ \\
\hline \multicolumn{4}{|l|}{ Coronary Artery Stenosis } \\
\hline \multicolumn{4}{|l|}{$(>50 \%)$} \\
\hline Left main stem & $42(53.8 \%)$ & $14(46.7 \%)$ & $0.504^{b}$ \\
\hline Left anterior descending artery & $74(94.9 \%)$ & $30(100 \%)$ & $0.574^{\mathrm{c}}$ \\
\hline Left circumflex artery & $65(83.3 \%)$ & $30(100 \%)$ & $0.018^{c}$ \\
\hline Right coronary artery & $69(88.5 \%)$ & $29(96.7 \%)$ & $0.278^{c}$ \\
\hline \multicolumn{4}{|l|}{ Laboratory Parameters } \\
\hline Haemoglobin, g/dL & $12.7 \pm 1.9$ & $15.2 \pm 1.2$ & $<0.001^{\mathrm{a}}$ \\
\hline Haematocrit, \% & $38.1 \pm 6.2$ & $44 \cdot 3 \pm 4.6$ & $<0.001^{\mathrm{a}}$ \\
\hline Blood urea, mg/dL & $7 \cdot 3 \pm 4 \cdot 4$ & $5 \cdot 5 \pm 1.6$ & $0.034^{\mathrm{a}}$ \\
\hline Creatinine, $\mathrm{mg} / \mathrm{dL}$ & $152 \pm 117.2$ & $119 \pm 22.1$ & $0.132^{\mathrm{a}}$ \\
\hline \multicolumn{4}{|l|}{ ASA Class } \\
\hline I or II & $10(12.8 \%)$ & $10(33 \cdot 3 \%)$ & $0.014^{\mathrm{b}}$ \\
\hline III and above & $68(87.2 \%)$ & $20(66.7 \%)$ & \\
\hline \multicolumn{4}{|l|}{ Operative Status } \\
\hline Elective & $75(96.2 \%)$ & $30(100 \%)$ & $0.559^{c}$ \\
\hline Emergency & $3(3.8 \%)$ & $\mathrm{o}(\mathrm{o} \%)$ & \\
\hline \multicolumn{4}{|l|}{ Surgery } \\
\hline Duration, minutes & $261 \pm 44.4$ & $264 \pm 35.9$ & $0.780^{a}$ \\
\hline $\begin{array}{l}\text { Cardiopulmonary bypass time, } \\
\text { minutes }\end{array}$ & $114 \pm 26.4$ & $105 \pm 20.2$ & $0.102^{\mathrm{a}}$ \\
\hline $\begin{array}{l}\text { Aortic cross clamp time, } \\
\text { minutes }\end{array}$ & $\begin{aligned} 82 & \pm 19.6 \\
3 & \pm 0.4\end{aligned}$ & $\begin{aligned} 78 & \pm 16.9 \\
3 & \pm 0.3\end{aligned}$ & $\begin{array}{l}0.332^{\mathrm{a}} \\
0.055^{\mathrm{a}}\end{array}$ \\
\hline Number of grafts & $54(69.2 \%)$ & $26(86.7 \%)$ & $0.064^{b}$ \\
\hline LIMA graft used & $3(3.8 \%)$ & $1(3 \cdot 3 \%)$ & $>0.95^{c}$ \\
\hline
\end{tabular}


Original Article | Adverse outcomes of RBC transfusions in CABG

Table 1. (continued)

Variables
$\begin{aligned} & \text { Transfused }(n=78) \\ & \text { Intra-operative or immediate }\end{aligned}$
Post-operative complications
Re-operation

Table 2. Comparison of outcomes between patients who received perioperative RBC transfusions and patients who did not

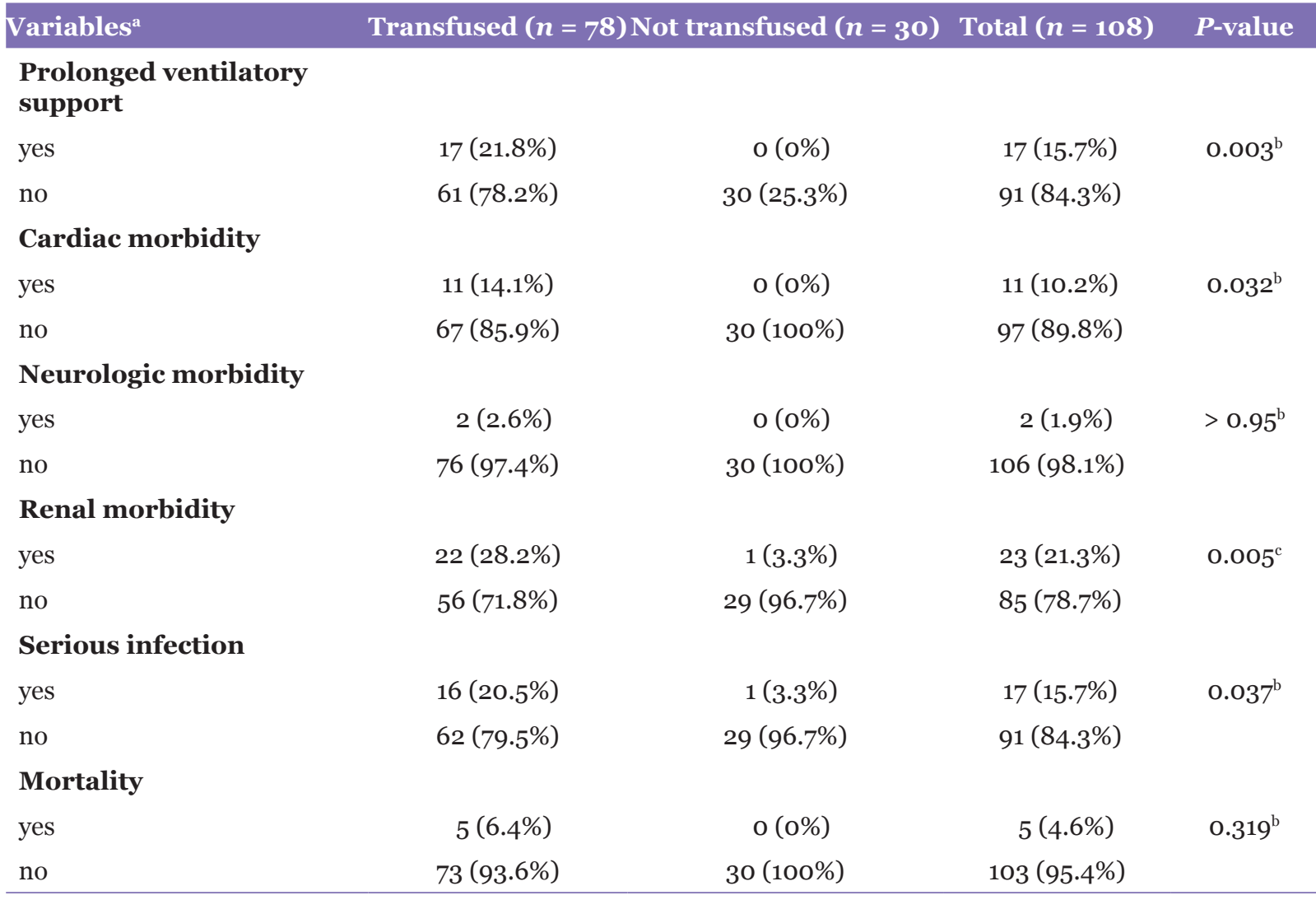


Table 3. Simple and multiple logistic regression analysis of factors associated with prolonged ventilatory support

\begin{tabular}{lccccc}
\multicolumn{5}{c}{ Odds ratio (OR) of factors } \\
Variable & $\mathrm{B}^{\mathrm{b}}$ & Wald & OR & 95\%CI & $P$-value \\
PRBC $^{\mathrm{d}}$, units & 0.643 & 5.364 & 1.90 & $1.10-3.28$ & 0.021 \\
Blood urea, mg/dL & 0.140 & 5.264 & 1.15 & $1.02-1.30$ & 0.022 \\
\multicolumn{1}{c}{ Adjusted odds ratio (AOR) of factor associated with prolonged ventilatory support } \\
Variable & $\mathrm{B}$ & Wald & AOR & $95 \% \mathrm{CI}$ & $P$-value \\
Constant & -3.006 & 35.168 & 0.49 & & $<0.001$ \\
PRBC, units & 0.373 & 14.118 & 1.45 & $1.20-1.77$ & $<0.001$ \\
Blood urea, mg/dL & 0.299 & 2.233 & 1.35 & $0.91-1.99$ & 0.135 \\
\hline
\end{tabular}

* Forward and backward stepwise likelihood ratio (LR) methods was applied

* No multi-collinearity and no interaction were found

* Hosmer Lemeshow test [Pearson chi-square test $(5)=5.932, P=0.313]$

* Classification table $85.2 \%$ correctly classified

* Area under receiver operating characteristics (ROC) curve was 0.797, $\mathrm{P}<0.001$

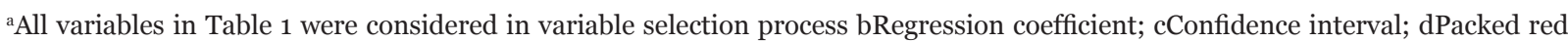
blood cell

Table 4. Simple and multiple logistic regression analysis of factors associated with cardiac morbidity

\begin{tabular}{|c|c|c|c|c|c|}
\hline \multicolumn{6}{|c|}{ OR of factors ${ }^{a}$ associated with cardiac morbidity } \\
\hline Variable & $\mathrm{B}^{\mathrm{b}}$ & Wald & OR & $95 \% \mathrm{CI}^{\mathrm{c}}$ & $P$-value \\
\hline $\mathrm{PRBC}^{\mathrm{d}}$, units & 0.434 & $13 \cdot 782$ & 1.54 & $1.23-1.94$ & $<0.001$ \\
\hline $\mathrm{CKD} / \mathrm{ESRD}^{\mathrm{e}}$ & 0.130 & 5.451 & 4.62 & $1.28-16.7$ & 0.020 \\
\hline $\mathrm{LVEF}^{\mathrm{f}} \leq 5 \mathrm{O} \%$ & 1.736 & $5 \cdot 962$ & 5.68 & $1.41-22.88$ & 0.015 \\
\hline NYHA $^{g}$ class 3 or 4 & 2.761 & 14.066 & 15.81 & $3 \cdot 74-66.91$ & $<0.001$ \\
\hline $\mathrm{CCF}^{\mathrm{h}}$ & 1.932 & $5 \cdot 575$ & 6.9 & $1.39-34.29$ & 0.018 \\
\hline Cardiogenic shock & 2.357 & 4.952 & 10.56 & $1.32-84.13$ & 0.026 \\
\hline Blood urea, mg/dL & 0.126 & 4.255 & 1.13 & $1.01-1.28$ & 0.039 \\
\hline \multicolumn{6}{|c|}{ AOR of factor associated with cardiac morbidity } \\
\hline Variable & B & Wald & AOR & $95 \% \mathrm{CI}$ & $P$-value \\
\hline Constant & -4.360 & 29.572 & 0.01 & & $<0.001$ \\
\hline PRBC, units & 0.337 & 7.156 & 1.40 & -1.79 & 0.007 \\
\hline NYHA class III or IV & 2.016 & 6.251 & $7 \cdot 51$ & $1.55-36.44$ & 0.012 \\
\hline
\end{tabular}

* Forward and backward stepwise likelihood ratio (LR) methods was applied

* No multicollinearity and no interaction were found

* Hosmer Lemeshow test [Pearson chi-square test $(5)=4.628, P=0.592]$

* Classification table 90.7\% correctly classified

* Area under receiver operating characteristics (ROC) curve was 0.915, $P<0.001$

${ }^{a}$ All variables in Table 1 were considered in variable selection process ${ }^{\mathrm{b}}$ Regression coefficient; ${ }^{\mathrm{c}}$ Confidence interval; ${ }^{\mathrm{d}}$ Packed red blood cells; ${ }^{\mathrm{e}}$ Chronic kidney disease/end stage renal disease; ${ }^{\mathrm{f}}$ Left ventricular ejection fraction; ${ }^{\mathrm{g}}$ New York Heart Association; ${ }^{\mathrm{h}}$ Congestive cardiac failure 
Original Article | Adverse outcomes of RBC transfusions in CABG

Table 5. Simple and multiple logistic regression analysis of factors associated with renal morbidity

\begin{tabular}{|c|c|c|c|c|c|}
\hline \multicolumn{6}{|c|}{ OR of factors ${ }^{a}$ associated with renal morbidity } \\
\hline Variable & $\mathrm{B}^{\mathrm{b}}$ & Wald & OR & $95 \% \mathrm{CI}^{\mathrm{c}}$ & $P$-value \\
\hline $\mathrm{PRBC}^{\mathrm{d}}$, units & 0.267 & 9.987 & 1.31 & $1.11-1.54$ & 0.002 \\
\hline Diabetes mellitus & 1.629 & 7.585 & 5.10 & $1.60-16.25$ & 0.006 \\
\hline CKD/ESRD ${ }^{\mathrm{e}}$ & 1.974 & 14.555 & 7.2 & $2.61-19.85$ & $<0.001$ \\
\hline Blood urea, mg/dL & 0.170 & 6.607 & 1.19 & $1.04-1.35$ & 0.010 \\
\hline \multicolumn{6}{|c|}{ AOR of factor associated with renal morbidity } \\
\hline Variable & B & Wald & $\mathrm{AOR}$ & $95 \% \mathrm{CI}$ & $P$-value \\
\hline Constant & -2.527 & 32.232 & 0.08 & & $<0.001$ \\
\hline PRBC, units & 0.203 & $5 \cdot 510$ & 1.23 & -1.45 & 0.019 \\
\hline CKD/ESRD & 1.659 & 9.339 & 5.25 & $1.81-15.22$ & 0.002 \\
\hline
\end{tabular}

* Forward and backward stepwise likelihood ratio (LR) methods was applied

* No multicollinearity and no interaction were found

* Hosmer Lemeshow test [Pearson chi-square test $(5)=4.594, P=0.597]$

* Classification table $78.7 \%$ correctly classified

* Area under receiver operating characteristics (ROC) curve was 0.792, $P<0.001$

${ }^{a}$ All variables in Table 1 were considered in variable selection process ${ }^{\mathrm{b}}$ Regression coefficient; ${ }^{\mathrm{c}}$ Confidence interval; ${ }^{\mathrm{d}}$ Packed red blood cells; ${ }^{\mathrm{e}}$ Chronic kidney disease/end stage renal disease

Table 6. Simple and multiple logistic regression analysis of factors associated with serious infection

\begin{tabular}{|c|c|c|c|c|c|}
\hline \multicolumn{6}{|c|}{ OR of factors ${ }^{a}$ associated with serious infection } \\
\hline Variable & $\mathrm{B}^{\mathrm{b}}$ & Wald & OR & $95 \% \mathrm{CI}^{\mathrm{c}}$ & $P$-value \\
\hline $\mathrm{PRBC}^{\mathrm{d}}$, units & 0.336 & 12.503 & 1.40 & $1.16-1.69$ & $<0.001$ \\
\hline Diabetes mellitus & 1.518 & 5.138 & $4 \cdot 57$ & $1.23-16.97$ & 0.023 \\
\hline $\mathrm{LVEF}^{\mathrm{e}} \leq 5 \mathrm{O} \%$ & 1.117 & 4.248 & 3.05 & $1.06-8.83$ & 0.039 \\
\hline 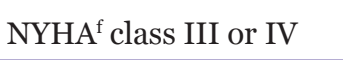 & 1.910 & 11.190 & 6.75 & $2.21-20.66$ & 0.001 \\
\hline \multicolumn{6}{|c|}{ AOR of factor associated with serious infection } \\
\hline Variable & B & Wald & AOR & $95 \% \mathrm{CI}$ & $P$-value \\
\hline Constant & -2.997 & 34.865 & 0.05 & & $<0.001$ \\
\hline PRBC, units & 0.267 & 6.837 & 1.31 & -1.60 & 0.009 \\
\hline NYHA class III or IV & 1.262 & 3.903 & 3.53 & $1.01-12.35$ & 0.048 \\
\hline
\end{tabular}

* Forward and backward stepwise likelihood ratio (LR) methods was applied

* No multicollinearity and no interaction were found

* Hosmer Lemeshow test [Pearson chi-square test $(5)=5.932, P=0.270$ ]

* Classification table $88.9 \%$ correctly classified

* Area under receiver operating characteristics (ROC) curve was 0.756, $P=0.001$

aAll variables in Table 1 were considered in variable selection process ${ }^{\mathrm{b}}$ Regression coefficient; ${ }^{\mathrm{c} C o n f i d e n c e ~ i n t e r v a l ;}$ dPacked red blood cells; ${ }^{\mathrm{e}}$ Left ventricular ejection fraction; ${ }^{\mathrm{f}} \mathrm{New}$ York Heart Association 


\section{Discussion}

The high prevalence of CAD worldwide and in Malaysia (2), with the increasing incidence of CAD over the years, has contributed to the major healthcare burden in the country (1). We sought to study the risk factors associated with morbidity and mortality of CABG because CABG is the main surgical intervention for CAD. Several studies have demonstrated the adverse outcomes associated with $\mathrm{RBC}$ transfusion in cardiac surgery and critically ill patients, but there is a lack of studies conducted in our country and in this region that have evaluated the adverse outcomes associated with transfusion of RBCs in CABG. Thus, this study was designed to compare the outcomes between patients who received perioperative RBC transfusions and those who did not. The results of this study showed that perioperative $\mathrm{RBC}$ transfusion is associated with adverse outcomes such as prolonged ventilatory support, cardiac morbidity, renal morbidity and serious infection. There is also a dose-dependent, increased risk for these complications with each unit of packed RBC transfusions.

According to the results of this study, among patients who underwent isolated CABG, the percentage of patients who required prolonged ventilatory support was $15.7 \%$; the percentage of those who developed cardiac morbidity, such as those with a low cardiac index or myocardial infarction, was $10.2 \%$; the percentage of those with neurologic morbidity, such as stroke, was $1.9 \%$; the percentage of those with renal morbidity (new onset renal failure requiring dialysis or acute kidney injury) was 21.3\%; the percentage of those with serious infection, including lung infection, mediastinitis, or sternal or leg wound infection was $15.7 \%$; and the percentage of those with 30-day/in-hospital mortality was $4.6 \%$. This study reported a higher incidence of these complications in our centre than other studies in other centres. According to the 2014 ESC/EACTS guidelines on myocardial revascularisation, the early clinical outcome 3 months after CABG is characterised by a $1 \%-2 \%$ mortality rate and a $1 \%-2 \%$ morbidity rate for each of the following events: stroke; renal, pulmonary and cardiac failure; bleeding; and wound infection (5).

RBC transfusion in cardiac surgery, including $\mathrm{CABG}$, is a common practice as seen in other surgical disciplines; the most common indications for perioperative RBC transfusion are pre-operative symptomatic anaemia, intra-operative excessive/life threatening bleeding or post-operative low haemoglobin levels. In our centre, the decision for blood transfusion was based on the patient's clinical status (symptomatic anaemia, intra-operative or post-operative excessive/life threatening bleeding, coagulopathies) and/or haemoglobin $<8 \mathrm{~g} / \mathrm{dL}$. However, throughout the years, a growing amount of literature has shown that RBC transfusion is associated with morbidity and short-term and long-term mortality after CABG (33-35). Although RBC transfusions may certainly have life-preserving value, the impact of smaller quantities of RBCs in a non-emergent setting (i.e., asymptomatic anaemia/bleeding) has not been well documented. These smallvolume transfusions are more discretionary and therefore potentially avoidable. A common rationale for $\mathrm{RBC}$ transfusion is to increase oxygen delivery to organ tissues sensitive to ischaemia in patients with haematocrit or haemoglobin levels below a predetermined and usually arbitrarily set lower limit. However, welldescribed changes in RBC morphology and the significant depletion of 2,3-diphosphoglycerate and nitric oxide levels that occur during storage are known to profoundly limit the capacity of these RBCs to carry and deliver oxygen to tissues. The accumulation of immunomodulating bioactive substances released from leukocytes to the storage medium and the transfusion of white blood cell-containing allogeneic RBC products have been associated with an increased risk of post-operative infection in cardiac surgery (15, 20). Thus, all of these outcomes have called into question the benefit of many of these types of transfusions.

This study demonstrated that perioperative RBC transfusion is significantly associated with prolonged ventilatory support $(P=$ 0.003), renal morbidity $(P=0.005)$, cardiac morbidity $(P=0.032)$ and serious infection $(P=0.037)$ after isolated CABG. This result corresponds to the results of a few published studies. Koch et al. in their observational cohort study in 2006 reported that perioperative RBC transfusion was associated with an increased risk of post-operative prolonged ventilatory support after isolated CABG (13). In 2012, Karkouti analysed 22 observational studies and concluded that perioperative blood transfusion was an independent risk factor for acute kidney injury (renal morbidity) in cardiac surgery (17). Surgenor et al. reported that intra-operative RBC transfusion during coronary artery bypass graft surgery increased the risk of post-operative 
low-output heart failure (cardiac morbidity) from their prospective observational study in 2006 (18). In a cohort study conducted in 389 patients by Rogers et al., their results showed that the transfusion of allogeneic blood products in cardiac surgery increased the risk of infection (19). Although the percentages of neurologic morbidity (transfused versus non-transfused, $2.6 \%$ versus $0 \%, P>0.05$ ) and post-operative mortality $(6.4 \%$ versus $0 \%, P>0.05)$ were higher in the transfused group than in the nontransfused group, the differences were not statistically significant. This is in contrast with results shown by Koch et al. and Murphy et al., who revealed that $\mathrm{RBC}$ transfusion in patients with cardiac surgery/isolated CABG is associated with neurologic adverse events and postoperative mortality $(13,14)$.

The number/unit of transfused RBCs is an independent risk factor for worse outcomes, including mortality. In a retrospective cohort study of 11,963 patients who underwent isolated CABG surgery, Koch et al. showed that perioperative $\mathrm{RBC}$ transfusion was associated with a dose-dependent increased risk of postoperative cardiac complications, serious infection, renal failure, neurologic complications, overall morbidity, prolonged ventilatory support, and in-hospital mortality (13). In a similar study, Murphy et al. showed that RBC transfusion was strongly associated with infection and postoperative ischaemic morbidity, hospital stay, increased early and late mortality, and hospital costs, and a strong dose-response relationship was present (14). Our study also showed a dosedependent increased risk of post-operative prolonged ventilatory support, cardiac events, renal complications and serious infection in isolated CABG patients with perioperative $\mathrm{RBC}$ transfusions. With a one-unit increase in packed $\mathrm{RBC}$ transfusions, there was an increased risk for prolonged ventilatory support (AOR, 1.45, 95\%CI, 1.20-1.77, $P<0.001)$, cardiac morbidity (AOR, 1.40, 95\%CI, 1.01-1.79; $P=0.007$ ), renal morbidity (AOR, 1.23, 95\%CI, 1.03-1.45; $P=$ o.019) and serious infection (AOR, 1.31, 95\%CI, 1.07-1.60; $P=0.009$ ).

In addition, we found that perioperative RBC transfusions were more common with characteristics of older age, female sex and low BMI as well as in patients with diabetes mellitus, hypertension, CKD/ESRD, a higher NYHA class (III or IV), low haemoglobin and haematocrit levels, a high blood urea level and a higher ASA class (III and above). However, these results were only found with univariable analyses. According to the literature, predictors for perioperative transfusion are re-operation, age, female sex, pre-operative haematocrit level, low ejection fraction, pre-operative serum creatinine level $(\geq 1.3 \mathrm{mg} / \mathrm{dL})$, and low body weight $(13,36-39)$.

Increasing evidence has shown that bloodconserving strategies are beneficial in cardiac surgery (40-46). As evidenced by a study conducted by Hajjar et al. in 2010 with a the transfusion requirement after cardiac surgery (TRACS) randomised controlled trial (RCT), 502 patients who underwent cardiac surgery were randomly assigned to a liberal strategy of blood transfusion (to maintain a haematocrit level $\geq$ $30 \%$ ) or to a restrictive strategy (haematocrit level $\geq 24 \%$ ); the study results showed that among patients undergoing cardiac surgery, the use of a restrictive perioperative transfusion strategy compared with a more liberal strategy resulted in non-inferior rates of the combined outcome of 30-day all-cause mortality and severe morbidity (47).

This study has its limitations because it was a retrospective, non-randomised study, and it introduced a substantial possibility of selection bias. It was a single-centre study that only involved the population of a single state (Kelantan) of Malaysia; the results could have been more representative if the study was performed at multiple centres across the nation. As is typical with a retrospective review of records, we were unable to obtain certain useful information, for example, the EuroSCORE risk stratification model, to assess the operative risk; this limitation could have been alleviated if the study was designed prospectively.

\section{Conclusion}

Perioperative RBC transfusion in isolated CABG is associated with adverse outcomes such as prolonged ventilatory support, cardiac morbidity, renal morbidity and serious infection. There is also a dose-dependent increase in the occurrence of these post-operative adverse events associated with packed RBC transfusions. Therefore, a more conservative approach of blood transfusion in cardiac surgery should be taken into consideration. 


\section{Acknowledgements}

We would like to thank the ethics committee who approved and allowed us to conduct this study. We thank Dr Chung Wai Keat and Dr Suria Junus who helped in designing this study. We also extend our gratitude to Associate Professor Dr Kamarul Imran Musa, Dr Wira Alfatah Ab Ayah @ Ab Aziz, Dr Ammar Sirri Ammar Ramzan, Professor Dr Norsa'adah Bachok and Dr Kueh Yee Cheng for their contribution in data analysis and comments on the manuscript.

\section{Conflict of Interests}

None.

\section{Funds}

None.

\section{Authors' Contributions}

Conception and design: $\mathrm{CCH}$

Analysis and interpretation of the data: $\mathrm{CCH}$

Drafting of the article: $\mathrm{CCH}$

Critical revision of the article for important intellectual content: MZG, AZM

Final approval of the article: MZG, AZM

\section{Correspondence}

Dr Chan Choon Hua

MD (Crimea State Medical University, Ukraine)

Department of Surgery,

School of Medical Sciences, Universiti Sains Malaysia, 16150 Kubang Kerian,

Kelantan, Malaysia.

Tel: $+6013-3388188$

Fax: +609-7653370

E-mail: chanchoonhua85@student.usm.my

\section{References}

1. Seong AC, John CKM. A review of coronary artery disease research in Malaysia. Med $J$ Malaysia. 2016;71:43.

2. World Health Organization. Global Health Observatory (GHO) data. [Internet]. Available from: http://www.who.int/gho/en/
3. Favaloro RG. Saphenous vein autograft replacement of severe segmental coronary artery occlusion. Ann Thorac Surg. 1968:5(4):334-339. https://doi.org/10.1016/Sooo3-4975(10)66351-5

4. Mohr FW, Morice MC, Kappetein AP, Feldman TE, Stahle E, Colombo A, et al. Coronary artery bypass graft surgery versus percutaneous coronary intervention in patients with threevessel disease and left main coronary disease: 5-year follow-up of the randomised, clinical SYNTAX trial. Lancet (London, England). 2013;381(9867):629-638. https://doi.org/10. 1016/So140-6736(13)60141-5

5. Windecker S, Kolh P, Alfonso F, Collet J-P, Cremer J, Falk V, et al. 2014 ESC/EACTS guidelines on myocardial revascularization: the task force on myocardial revascularization of the European Society of Cardiology (ESC) and the European Association for Cardio-Thoracic Surgery (EACTS). Developed with the special contribution of the European Association of Percutaneous Cardiovascular Interventions (EAPCI). Eur Heart J. 2014;35(37):2541-2619. https://doi. org/10.1093/eurheartj/ehu278

6. Hillis LD, Smith PK, Anderson JL, Bittl JA, Bridges CR, Byrne JG, et al. 2011 ACCF/AHA guideline for coronary artery bypass graft surgery. Circulation. 2011:124(23):e652-e735. https:// doi.org/10.1161/CIR.obo13e31823co74e

7. Horvath KA, Acker MA, Chang H, Bagiella E, Smith PK, Iribarne A, et al. Blood transfusion and infection after cardiac surgery. Ann Thorac Surg. 2013;95(6):2194-2201. https://doi. org/10.1016/j.athoracsur.2012.11.078

8. DeFoe GR, Ross CS, Olmstead EM, Surgenor $\mathrm{SD}$, Fillinger MP, Groom RC, et al. Lowest hematocrit on bypass and adverse outcomes associated with coronary artery bypass grafting. Northern New England cardiovascular disease study group. Ann Thorac Surg. 2001;71(3):769776. https://doi.org/10.1046/j.1445-1433.2001. 02258.x

9. Ranucci M, Biagioli B, Scolletta S, Grillone G, Cazzaniga A, Cattabriga I, et al. Lowest hematocrit on cardiopulmonary bypass impairs the outcome in coronary surgery: An Italian multicenter study from the national cardioanesthesia database. Tex Heart Inst J. 2006;33(3):300. 
10. Bilgin YM, van de Watering LM, Versteegh MI, van Oers $\mathrm{MH}$, Brand A. Effects of allogeneic leukocytes in blood transfusions during cardiac surgery on inflammatory mediators and postoperative complications. Crit Care Med. 2010;38(2):546-52. https://doi.org/10.1097/ CCM.obo13e3181code7b

11. Stone GW, Clayton TC, Mehran R, Dangas G, Parise H, Fahy M, et al. Impact of major bleeding and blood transfusions after cardiac surgery: analysis from the acute catheterization and urgent intervention triage strategY (ACUITY) trial. Am Heart J. 2012;163(3):522-529. https://doi. org/10.1016/j.ahj.2011.11.016

12. Reeves BC, Murphy GJ. Increased mortality, morbidity, and cost associated with red blood cell transfusion after cardiac surgery. Curr Opin Cardiol. 2008;23(6):607-612. https://doi. org/10.1097/HCO.obo13e328310fc95

13. Koch CG, Li L, Duncan AI, Mihaljevic T, Cosgrove DM, Loop FD, et al. Morbidity and mortality risk associated with red blood cell and blood-component transfusion in isolated coronary artery bypass grafting. Crit Care Med. 2006;34(6):1608-1616. https://doi. org/10.1097/o1.CCM.0000217920.48559.D8

14. Murphy GJ, Reeves BC, Rogers CA, Rizvi SI, Culliford L, Angelini GD. Increased mortality, postoperative morbidity, and cost after red blood cell transfusion in patients having cardiac surgery. Circulation. 2007;116(22):2544-2552. https:// doi.org/10.1161/CIRCULATIONAHA.107.698977

15. Paone G, Likosky DS, Brewer R, Theurer PF, Bell GF, Cogan CM, et al. Transfusion of 1 and 2 units of red blood cells is associated with increased morbidity and mortality. Ann Thorac Surg. 2014;97(1):87-94. https://doi.org/10.1016/j. athoracsur.2013.07.020

16. Spiess BD, editor Transfusion of blood products affects outcome in cardiac surgery. Semin Cardiothorac Vasc Anesth. 2004;8(4):267-281. https://doi.org/10.1177/108925320400800402

17. Karkouti K. Transfusion and risk of acute kidney injury in cardiac surgery. $\mathrm{Br} J$ Anaesth. 2012;109(Suppl 1):i29-i38. https://doi.org/ 10.1093/bja/aes422
18. Surgenor SD, DeFoe GR, Fillinger MP, Likosky DS, Groom RC, Clark C, et al. Intraoperative red blood cell transfusion during coronary artery bypass graft surgery increases the risk of postoperative low-output heart failure. Circulation. 2006;114(Suppl 1):I-43-I-48. https://doi.org/10.1161/CIRCULATIONAHA.105. 001271

19. Rogers MA, Blumberg N, Heal JM, Hicks $\mathrm{J}$, George L. Increased risk of infection and mortality in women after cardiac surgery related to allogeneic blood transfusion. J Women's Health. 2007;16(10):1412-1420. https://doi. org/10.1089/jwh.2007.0397

20. Andreasen JJ, Dethlefsen C, Modrau IS, Baech J, Schonheyder HC, Moeller JK, et al. Storage time of allogeneic red blood cells is associated with risk of severe postoperative infection after coronary artery bypass grafting. Eur $J$ Cardiothorac Surg. 2011;39(3):329-334. https://doi.org/10.1016/j. ejcts.2010.06.019

21. Galas FR, Almeida JP, Fukushima JT, Osawa EA, Nakamura RE, Silva CM, et al. Blood transfusion in cardiac surgery is a risk factor for increased hospital length of stay in adult patients. $J$ Cardiothorac Surg. 2013;8(1):54. https://doi. org/10.1186/1749-8090-8-54

22. Vamvakas E, Carven J. RBC transfusion and postoperative length of stay in the hospital or the intensive care unit among patients undergoing coronary artery bypass graft surgery: the effects of confounding factors. Transfusion. 2000;40(7):832-839. https://doi.org/10.1046/ j.1537-2995.2000.40070832.x

23. Wan Ahmad WA, Sim KH. eds. Annual Report of the NCVD-ACS Registry 2009 \& 2010. [Internet]. Kuala Lumpur, Malaysia: National Cardiovascular Disease Database Malaysia; 2013. Available from: http://www.acrm.org.my/ncvd/pciReport_o9. php

24. Engoren MC, Habib RH, Zacharias A, Schwann TA, Riordan CJ, Durham SJ. Effect of blood transfusion on long-term survival after cardiac operation. Ann Thorac Surg. 2002;74(4):11801186. https://doi.org/10.1016/Sooo3-4975(02) 03766-9 
25. Kuduvalli M, Oo AY, Newall N, Grayson AD, Jackson M, Desmond MJ, et al. Effect of perioperative red blood cell transfusion on 30-day and 1-year mortality following coronary artery bypass surgery. Eur $J$ Cardiothorac Surg. 2005;27(4):592-598. https://doi.org/10.1016/j. ejcts.2005.01.030

26. Siregar S, Groenwold RH, de Mol BA, Speekenbrink RG, Versteegh MI, Brandon Bravo Bruinsma GJ, et al. Evaluation of cardiac surgery mortality rates: 30-day mortality or longer followup? Eur J Cardiothorac Surg. 2013;44(5):875883. https://doi.org/10.1093/ejcts/ezt119

27. Bhaskar B, Dulhunty J, Mullany DV, Fraser JF. Impact of blood product transfusion on short and long-term survival after cardiac surgery: more evidence. Ann Thorac Surg. 2012;94(2):46o-467. https://doi.org/10.1016/j. athoracsur.2012.04.005

28. Koch CG, Khandwala F, Li L, Estafanous FG, Loop FD, Blackstone EH. Persistent effect of red cell transfusion on health-related quality of life after cardiac surgery. Ann Thorac Surg. 2006;82(1):13-20. https://doi.org/10.1016/j. athoracsur.2005.07.075

29. Koch CG, Li L, Duncan AI, Mihaljevic T, Loop FD, Starr NJ, et al. Transfusion in coronary artery bypass grafting is associated with reduced long-term survival. Ann Thorac Surg. 2006;81(5):1650-1657. https://doi. org/10.1016/j.athoracsur.2005.12.037

30. Jakobsen C-J, Ryhammer PK, Tang M, Andreasen JJ, Mortensen PE. Transfusion of blood during cardiac surgery is associated with higher longterm mortality in low-risk patients. Eur $J$ Cardiothorac Surg. 2012;42(1):114-120. https:// doi.org/10.1093/ejcts/ezr242

31. Van Straten AH, Bekker MW, Soliman Hamad MA, van Zundert AA, Martens EJ, Schönberger JP, et al. Transfusion of red blood cells: the impact on short-term and long-term survival after coronary artery bypass grafting, a ten-year follow-up. Interact Cardiovasc Thorac Surg. 2010;10(1):37-42. https://doi.org/10.1510/icvts. 2009.214551
32. Ponikowski P, Voors AA, Anker SD, Bueno $\mathrm{H}$, Cleland JG, Coats AJ, et al. 2016 ESC guidelines for the diagnosis and treatment of acute and chronic heart failure. Eur Heart $J$. 2016;18(8):891-975. https://doi.org/10.1002/ ejhf.592

33. Paone G, Herbert MA, Theurer PF, Bell GF, Williams JK, Shannon FL, et al. Red blood cells and mortality after coronary artery bypass graft surgery: an analysis of 672 operative deaths. Annals Thorac Surg. 2015;99(5):1583-1590. https://doi.org/10.1016/j.athoracsur.2014.12.064

34. Hung M, Besser M, Sharples L, Nair S, Klein A. The prevalence and association with transfusion, intensive care unit stay and mortality of preoperative anaemia in a cohort of cardiac surgery patients. Anaesthesia. 2011;66(9):812-818. https://doi.org/10.1111/j.1365-2044.2011.06819.x

35. Campos IC, Tanganelli V, Maues HP, Coelho MCM, Martins FA, Munhoz G, et al. Blood transfusion and increased perioperative risk in coronary artery bypass grafts. Braz $J$ Cardiovasc Surg. 2017;32(5):394-400. https://doi.org/10. 21470/1678-9741-2017-0034

36. Elmistekawy EM, Errett L, Fawzy HF. Predictors of packed red cell transfusion after isolated primary coronary artery bypass grafting-the experience of a single cardiac center: a prospective observational study. $J$ Cardiothorac Surg. 2009;4(1):20. https://doi. org/10.1186/1749-8090-4-20

37. Lopes CT, Brunori EH, Cavalcante AM, Moorhead SA, Lopes Jde L, Barros AL. Predictors of red blood cell transfusion after cardiac surgery: a prospective cohort study. Revista da Escola de Enfermagem da USP. 2015;49(6):914-922. https://doi.org/10.1590/Soo8o-6234201500006 00006

38. Sandoughdaran S, Sarzaeem MR, Bagheri J, Jebelli M, Mandegar MH. Predictors of blood transfusion in patients undergoing coronary artery bypass grafting surgery. Int Cardiovasc Res J. 2013;7(1):25-28.

39. Shoukat S, Gowani SA, Khimani F, Khan FA, Zaman M, Sharif H. Predictive model of blood transfusion during CABG surgery in Pakistan. J Pak Med Assoc. 2008;58(8):421-426. 
Original Article | Adverse outcomes of RBC transfusions in CABG

40. Moskowitz DM, McCullough JN, Shander A, Klein JJ, Bodian CA, Goldweit RS, et al. The impact of blood conservation on outcomes in cardiac surgery: is it safe and effective? Ann Thorac Surg. 2010;90(2):451-458. https://doi.org/10.1016/j. athoracsur.2010.04.089

41. Hébert PC, Yetisir E, Martin C, Blajchman MA, Wells G, Marshall J, et al. Is a low transfusion threshold safe in critically ill patients with cardiovascular diseases? Crit Care Med. 2001;29(2):227-234. https://doi. org/10.1097/00003246-200102000-00001

42. LaPar DJ, Crosby IK, Ailawadi G, Ad N, Choi E, Spiess BD, et al. Blood product conservation is associated with improved outcomes and reduced costs after cardiac surgery. $J$ Thorac Cardiovasc Surg. 2013;145(3):796-804. https://doi. org/10.1016/j.jtcvs.2012.12.041

43. Pattakos G, Koch CG, Brizzio ME, Batizy LH, Sabik JF, Blackstone EH, et al. Outcome of patients who refuse transfusion after cardiac surgery: a natural experiment with severe blood conservation. Arch Intern Med. 2012;172(15):1154-1160. https:// doi.org/10.1001/archinternmed.2012.2449
44. Ferraris VA, Ferraris SP, Saha SP, Hessel EA, Haan CK, Royston BD, et al. Perioperative blood transfusion and blood conservation in cardiac surgery: the Society of Thoracic Surgeons and the Society of Cardiovascular Anesthesiologists clinical practice guideline. Ann Thorac Surg. 2007;83(Suppl 5):S27-S86. https://doi. org/10.1016/j.athoracsur.2007.02.099

45. Cosgrove DM, Thurer RL, Lytle BW, Gill CG, Peter M, Loop FD. Blood conservation during myocardial revascularization. Ann Thorac Surg. 1979;28(2):184-189. https://doi.org/10.1016/ Sooo3-4975(10)63778-2

46. Ternström L, Hyllner M, Backlund E, Schersten H, Jeppsson A. A structured blood conservation programme reduces transfusions and costs in cardiac surgery. Interact Cardiovasc Thorac Surg. 2014;19(5):788-794. https://doi.org/10.1093/ icvts/ivu266

47. Hajjar LA, Vincent JL, Galas FR, Nakamura RE, Silva CM, Santos MH, et al. Transfusion requirements after cardiac surgery: the TRACS randomized controlled trial. JAMA. 2010;304(14):1559-1567. https://doi.org/10. 1001/jama.2010.1446 